\title{
Driven To Extinction? The Ethics of Eradicating Mosquitoes With Gene-Drive Technologies
}

\begin{abstract}
Mosquito-borne diseases such as Malaria, Chikungunya, and Dengue fever represent a significant global disease burden. Recent outbreaks of such diseases have led to calls to reduce populations of the Anopheles gambiae, Anopheles stephensi, and Aedes aegypti species of mosquitos that are amongst the primary vectors of these diseases. Until recently, such efforts to reduce mosquito populations have been limited by the relatively ineffective methods employed, including fumigation of affected areas, and the removal of mosquito breeding sites. However, advances in 'gene-drive' technology have raised the prospect of eradicating these species of mosquito via genetic modification. Recently published studies on this technology have attracted a great deal of media attention, and the idea of using gene-drive technology to eradicate mosquitoes has been met with criticism in the public domain. In this paper, I shall dispel two moral objections to the use of gene-drive technologies to eradicate mosquitoes, and suggest that we need to acquire more empirical data to adequately inform our moral analysis of this technology.
\end{abstract}

\section{The Global Disease Burden of Mosquito-Borne Diseases and Gene Drive Technology}

World Health Organization (WHO) estimates (released in December 2015) suggest that there were 214 million cases of malaria in 2015, resulting in 438000 deaths.(1) There have also been explosive outbreaks of dengue and chikungunya in the past decade, although these viruses are less lethal than malaria; an estimated 500000 people are hospitalized with severe dengue each year, and about $2.5 \%$ of those affected die.(2) Similarly, only 191 deaths have been attributed to chikungunya between December 2013 and April 2015, out of over 1379788 suspected recorded cases.(3) Finally, during the composition of this paper, WHO announced that outbreak of the mosquito-borne Zika virus in Latin America represented a public health emergency of international concern, due to the virus' suspected (although at the time of writing unproven) link to cases of microcephaly and other neurological disorders.(4)

There is currently no commercially available vaccine for any of the above viruses, and there is also no specific antiviral cure for Zika, Chikungunya or Dengue. Malaria can be cured if it is diagnosed and treated promptly. However, this is not always possible, especially in under-resourced countries where the disease is prevalent.

Mosquito-borne diseases represent a significant global disease burden; we thus have a significant moral reason to seek to eradicate the vectors of these diseases. Gene-drive technology represents a promising new avenue in this regard. Gene-drive technology seeks to facilitate the biased inheritance of particular genes throughout an entire 
This is a Pre-Publication Version - Post copy-edited version published at http://jme.bmj.com/content/early/2016/04/26/medethics-2016103462.abstract

species by genetically modifying some members of that species. Modified members of the species will, it is hoped, pass on targeted genes to its offspring. Using the CRISPR-Cas9 editing system, two recent studies have suggested that gene-drive technology could be used to reduce the global disease burden of mosquito-borne diseases. In one study, Gantz et al. modified the Anopheles stephensi species of mosquito to resist the Plasmodium parasite that causes malaria.(5) In another, Hammond et al. modified the Anopheles gambiae mosquito to pass on genes that cause infertility in female offspring.(6) In both studies, the gene-drive technique was highly efficient in passing the selected gene on to the offspring of the modified mosquitoes; nonetheless, further studies are required to establish that genetic modifications would be passed down over multiple generations, and that modified mosquitoes would compete successfully for mates in the wild.

I shall, for a number of reasons, focus on the ethics of gene-drive strategies that aim to eradicate mosquito species, rather than those that aim to induce resistance to a disease pathogen amongst mosquito populations. First, the former strategy is more controversial because it raises ethical questions about the permissibility of eradicating a species. Second, a gene-drive strategy aimed at eradicating a mosquito species is already being field-tested (albeit amidst some degree of controversy)(7) by the British firm Oxitec, unlike strategies aimed at inducing resistance to pathogens amongst mosquito populations. As such, the ethical questions raised by this gene-drive strategy are particularly pressing. Third, gene-drive strategies aimed at eradicating mosquito species are likely to have more success in achieving a long-term reduction of mosquito-borne disease. As Kevin Esvelt suggested in a recent news item in Nature, whilst it seems plausible to suppose that a parasite like the plasmodium parasite would evolve resistance to the genetic modification we might make to mosquitoes, mosquito elimination strategies would require the parasite to find a new host species.(8)

\section{The Sanctity of Life}

Is there anything intrinsically wrong with bringing about the extinction of another species? In objecting to species eradication as a form of pest control, the entomologist R.L Metcalf wrote that ". . . species should be regarded as sacred and man indeed has no right to destroy them” (9). Melanie Challenger echoed this appeal to the sanctity of life in the current controversy surrounding gene-drive technologies, in comments published in a Guardian newspaper article:

Is there a more intrinsic philosophical reason why we shouldn’t drive an animal to extinction? ... My instinct is: yes. . . the sanctity of life. (10)

As Peter Singer reminds us, when people say that 'all life is sacred' they “. . . almost never mean what they say".(11) If they did, then most people would be professing a view that is hopelessly inconsistent with their everyday practices, since people regularly destroy living things for their own ends. For instance, most people do not believe that it is wrong to kill vegetables and fruit by picking them, or to take 
This is a Pre-Publication Version - Post copy-edited version published at http://jme.bmj.com/content/early/2016/04/26/medethics-2016103462.abstract

antibiotics that destroy bacteria. A more plausible view on this matter is to claim that the morally permissibility of killing a living thing depends on whether it has moral status. For a creature to have moral status means that the creature deserves certain forms of moral protection, and a creature's moral status is often said to depend on the kinds of capacities it has. Of course, we believe that human beings have a particularly high moral status; for many philosophers, this is because humans have the capacities for rationality and self-consciousness over time, unlike many other non-human animals.(12) In contrast, fruit, vegetables, and bacteria are normally not understood to have capacities of the sort that confer moral status.

However, the question may not be simply whether individual mosquitoes have moral status. An adherent of the sanctity of life view in this context could maintain that even if we assume that individual members of a species are not 'sacred', the species considered holistically still may be. Indeed, this is a natural reading of Metcalf's claim above. However, this is a highly contestable mereological view; how could moral status be an emergent property of a species whose members do not have moral status? Russow has also provided powerful arguments against the idea of claiming that obligations to a species might arise out of certain putative rights or interests of a species; how could a species, considered holistically, be said to have such rights or interests?(13) Some environmentalist ethicists might claim that there can be other grounds for ascribing non-moral value to species at the holistic level (14). However, even if we accept that we might have some reason to conserve a species whose individual members lack moral status, to claim that this reason would outweigh our reasons safeguard human health is inconsistent with the widely accepted claim that the intentional eradication of a species was in fact one of modern medicine's greatest triumphs. Through an extensive vaccination programme in the twentieth century, we intentionally eradicated the variola species of virus responsible for smallpox, a devastating infectious disease. If the adherent of the sanctity of life view is understood to be claiming that 'all living species are sacred' then this vaccination programme would have amounted to a morally abhorrent form of 'speciecide'; this though is surely a reductio ad absurdum of the position.

To avoid this, the opponent of gene-driven eradication who claims that it is intrinsically wrong to bring about the extinction of mosquitoes ought to claim that we have a moral reason not to eradicate mosquito species that does not apply to viruses and other basic life-forms. However, this strategy puts the onus on the objector to explain why this reason applies to mosquitoes but not to viruses. To do so, it seems that they must appeal to a more nuanced picture whereby not all living things (or species) have moral status, rather than to 'the sanctity of life per se.

To return to the Singerian view of moral status, individual non-human animals may have a degree of moral status, even if they lack the rationality and self-consciousness of humans. As Singer suggests, we might attribute moral status to a non-human animal because it is sentient or conscious. At least on utilitarian views, we have a moral reason to refrain from causing pain to a sentient being, or from killing a being that has an interest in continuing to survive.(11)

As Russow points out in her analysis, it is not clear that these capacities can be attributed to a species at the holistic level.(13) Furthermore, even before we consider the empirical question of whether individual mosquitoes are sentient in a manner that 
This is a Pre-Publication Version - Post copy-edited version published at http://jme.bmj.com/content/early/2016/04/26/medethics-2016-

103462.abstract

could undergird some degree of moral status, it should be acknowledged that even if the above Singerian claims mean that we have a moral reason not to eradicate a sentient species by killing its existing members (with pesticides, for example), this does not entail that we have a moral reason not to eradicate that species through genedrive technology. The latter, unlike the former, would not involve causing any individual sentient being to die prematurely; rather the species could just be phased out over time. In the current context, if Hammond et al.'s technique were successfully used to eradicate mosquitoes, individual mosquitoes would live and die in the same way that they would have done in the absence of the intervention; they will just fail to reproduce. ${ }^{1}$

Whether utilitarian should oppose the phasing out of a sentient species in this way depends on whether they adhere to what Singer describes as total utilitarianism or a prior existence version of the view.(11) According to total utilitarianism we should increase the amount of pleasure in the world, and it makes little difference whether we do this by increasing the pleasure of existing beings or by increasing the number of beings with pleasurable lives. The prior existence view denies this second clause, claiming that only the pleasures of existing sentient beings should feature in our moral calculus. This difference means that it is not clear that 'prior existence' utilitarians could oppose eradicating a sentient species by genetically modifying it to become infertile, if the intervention did not lead to them being killed prematurely. Of course, a holder of the prior existence view might object to this strategy if awareness of an inability to reproduce caused suffering to modified members of the species. However, such awareness would require cognitive capacities that go far beyond mere sentience.

In contrast, 'total' utilitarians might claim that we have a moral reason to refrain from eradicating a species that is capable of living a pleasurable life. However, this does not entail that they should oppose the gene-driven eradication of mosquitoes for two reasons. First, it is not clear that mosquitoes bear valuable capacities such as consciousness or sentience that might make it appropriate to afford them a significant degree of moral status. For instance, although their view is not supported by all entomologists,(16) in their review of the relevant literature, Eismeann et al. concluded that:

. . . the evidence from consideration of the adaptive role of pain, the neural organization of insects and observations of their behaviour does not appear to support the occurrence in insects of a pain state.(17)

Second, even if mosquitoes are sentient (and can be expected to have lives worth living), I have thus far been ignoring the current global disease burden of mosquitoborne diseases in the total utilitarian's moral analysis. In view of the fact that the continued existence of mosquitoes is likely to lead to the death of a considerable number of persons, and great deal of other human suffering, the total utilitarian can quite consistently claim that we have a stronger moral reason to eradicate mosquitoes than we have to ensure their continued existence.

\footnotetext{
1 It should be noted that Oxitec report that the modification they use prematurely kills the mosquito before it reaches fertility.(15)
} 
This is a Pre-Publication Version - Post copy-edited version published at http://jme.bmj.com/content/early/2016/04/26/medethics-2016103462.abstract

\section{Playing God - Promethean Aspirations?}

Technological interventions that aim to radically alter the natural world are often criticised on the basis that such interventions amount to 'playing God', or of incorporating Promethean aspirations. $(18,19)^{2}$ Gene-drive technology is a natural target for this objection. Indeed, Helen Wallace, executive director of the UK watchdog GeneWatch, invoked the spirit of this objection in the context of genedriven mosquitoes by describing modified mosquitoes as "Dr. Frankenstein's monster, plain and simple”(21)

This form of objection is also familiar from the widely discussed human enhancement debate. Michael Sandel has famously objected to the "Promethean aspiration to mastery" that is inherent to the pursuit of human enhancement, urging us to instead harbour a 'respect for the given'.(22) A number of criticisms have been raised against Sandel's arguments,(23) and similar considerations can also be raised against the analogous objection to gene-drive mosquitoes. Contra Sandel, we sometimes take ourselves to have sufficient reasons to seek to improve upon the given. Consider again, for example, our success in eradicating the variola virus responsible for smallpox. It is not clear why this should be understood to have amounted to displaying an attitude of mastery rather than compassion. Even if the former description were more fitting, the fact that the eradication of smallpox has saved millions of lives surely outweighs the moral wrong of displaying a hubristic attitude.

The playing God objection is pernicious because it contains a grain of truth, which is that we face a great deal of uncertainty when we think about the effects that genedrive technologies might have; and this might plausibly give us an extrinsic reason not to use the technology. The scientific opinion on the question of the likely longterm ecological consequences of eradicating mosquitoes is mixed, with some entomologists claiming that mosquitoes are a vital food source and pollinator, whilst others claim that mosquitoes do not occupy an unassailable niche in the environment.(24) On the other hand, we cannot be certain that gene-drive technology will be successful in eradicating mosquitoes. For it to do so, modified mosquitoes would have to mate with 'natural' mosquitoes in the wild in order to pass on the modified genes, and these genes would have to be passed down multiple generations; neither is certain to occur.

What is the correct approach to take in the face of these epistemic limitations? The mistake that many of those who press the playing God objection make is to think that any uncertainty about the potential risks and benefits of using a novel biotechnology entails that we should not use it. Yet, nearly all new technologies may have unpredictable effects on future generations.(ref omitted) To claim that this means that we should not develop and use any technology that might have unforeseen or unintended side-effects is not only to be risk averse in the extreme, it is also to be inconsistent with the approach we have historically taken to other new technologies,

\footnotetext{
${ }^{2}$ I have considered the playing God objection to gene-drive techniques aimed at inducing pathogen resistance amongst mosquito populations in (20). Some of the arguments I make in this section are analogous to the arguments found in this other work.
} 
This is a Pre-Publication Version - Post copy-edited version published at http://jme.bmj.com/content/early/2016/04/26/medethics-2016103462.abstract

such as artificial reproductive technologies and information technologies that also posed risks at the time of their initial deployment.

I claim that we should advocate an approach of epistemic humility, without making the implausible assumption that this requires us to abandon the development of a biotechnology in the face of any kind of risk. In the current context, advocates of gene-drive technology should admit the extent of the uncertainty we face, and support efforts to reduce it. In order to make an informed decision about whether it is prudent to seek to eradicate mosquitoes using gene-drive technology, we need more data about, inter alia, the likely effects of such eradication on the ecosystem and the likelihood of gene-drive technology successfully eradicating the intended species. At some point, this might require us to make a leap of faith and commit to a widespread field trial; if this comes to be the case, then it is imperative that we believe that the expected benefit of the trial outweighs the negative risks, and that there is full and open disclosure about the nature of the trials and its potential effects.

To conclude, it is true that we need to thoroughly analyse the possible negative consequences of gene-drive technologies. We may conclude that the risks outweigh the potential benefits; then we should refrain from using the technology and pursue other avenues in our fight against mosquito-borne diseases. It might be that our analysis shows that genetically modifying mosquitoes to induce resistance to specified pathogens may be less risky and just as effective at reducing the global disease burden. Then we would plausibly have a significant moral reason to prefer this kind of modification. In weighing the potential negative consequences of using either kind of gene-drive strategy, we should consider not only the badness of the worst-case scenario we might face, but also the likelihood of it actually occurring. It is well known that we humans are inept at understanding risk; as Cass Sunstein points out, when considering negative risks, we tend to ". . . focus on the adverse outcome, not on its likelihood. . . (we) are not closely attuned to the probability that harm will occur".(26) In order to guard against this bias, and to accurately assess the risks of gene-drive technology, we need to acquire more data and attend to the probabilities that it suggests, not just the nature of the harms.

Moreover, we should not take the potential benefits of using gene-drive technologies lightly. The status quo situation is one in which hundreds of thousands of lives are being lost each year. We should not refrain from seeking to develop a technology that shows significant promise of changing the status quo for the better. As with any novel technology, we cannot tell for sure what will happen; but we can make informed decisions that can have profound effects on many people's lives.

\section{References}

1. World Health Organization. WHO | Malaria [Internet]. WHO. 2016 [cited 2016 Feb 11]. Available from: http://www.who.int/mediacentre/factsheets/fs094/en/

2. World Health Organization. Dengue and severe dengue [Internet]. 2015. Available from: http://www.who.int/mediacentre/factsheets/fs117/en/ 
This is a Pre-Publication Version - Post copy-edited version published at http://jme.bmj.com/content/early/2016/04/26/medethics-2016103462.abstract

3. World Health Organization. WHO | Chikungunya [Internet]. WHO. 2015 [cited 2016 Feb 11]. Available from: http://www.who.int/mediacentre/factsheets/fs327/en/

4. World Health Organization. WHO | WHO statement on the first meeting of the International Health Regulations (2005) (IHR 2005) Emergency Committee on Zika virus and observed increase in neurological disorders and neonatal malformations [Internet]. WHO. 2016 [cited 2016 Feb 11]. Available from: http://www.who.int/mediacentre/news/statements/2016/1stemergency-committee-zika/en/

5. Gantz VM, Jasinskiene N, Tatarenkova O, Fazekas A, Macias VM, Bier E, et al. Highly efficient Cas9-mediated gene drive for population modification of the malaria vector mosquito Anopheles stephensi. Proc Natl Acad Sci [Internet]. 2015 Dec 8 [cited 2016 Feb 15];112(49):E6736-43. Available from: http://www.pnas.org/content/112/49/E6736

6. Hammond A, Galizi R, Kyrou K, Simoni A, Siniscalchi C, Katsanos D, et al. A CRISPR-Cas9 gene drive system targeting female reproduction in the malaria mosquito vector Anopheles gambiae. Nat Biotechnol [Internet]. 2016 Jan [cited 2016 Feb 15];34(1):78-83. Available from: http://www.nature.com/nbt/journal/v34/n1/full/nbt.3439.html

7. Subbaraman N. Science snipes at Oxitec transgenic-mosquito trial. Nat Biotechnol [Internet]. 2011 Jan [cited 2016 Feb 15];29(1):9-11. Available from: http://www.nature.com/nbt/journal/v29/n1/full/nbt0111-9a.html

8. Callaway E. Mosquitoes engineered to pass down genes that would wipe out their species. Nature [Internet]. 2015 Dec 7 [cited 2016 Feb 15]; Available from: http://www.nature.com/doifinder/10.1038/nature.2015.18974

9. Perkins J. The Philosophical Foundations. In: Perkins J, editor. Insects, Experts, and the Insecticide Crisis: The Quest for New Pest Management Strategies. Springer Science \& Business Media; 2012. p. 183-207.

10. Bl A. Should we wipe mosquitoes off the face of the Earth? The Guardian [Internet]. 2016 Feb 10 [cited 2016 Feb 15]; Available from: http://www.theguardian.com/global/2016/feb/10/should-we-wipemosquitoes-off-the-face-of-the-earth

11. Singer P. Practical ethics [electronic resource]. 3rd ed. New York: Cambridge University Press; 2011. xiii+337 p.

12. Tooley M. Abortion and Infanticide. Philos Public Aff. 1972;2(1):37-65.

13. Russow L-M. Why do species matter? Environ Ethics. 1981;3(2):101-12. 
This is a Pre-Publication Version - Post copy-edited version published at http://jme.bmj.com/content/early/2016/04/26/medethics-2016103462.abstract

14. O’Neil R. Intrinsic Value, Moral Standing, and Species. Environ Ethics. 1997;19(1):45-52.

15. Oxitec. Oxitec: How it works [Internet]. 2016. Available from: http://www.oxitec.com/health/how-it-works/

16. Lockwood JA. The Moral Standing of Insects and the Ethics of Extinction. Fla Entomol. 1987;70(1):70-89.

17. Eisemann $\mathrm{CH}$, Jorgensen WK, Merritt DJ, Rice MJ, Cribb BW, Webb PD, et al. Do insects feel pain? - A biological view. Experientia [Internet]. $1984 \mathrm{Feb}$ [cited 2016 Feb 15];40(2):164-7. Available from: http://link.springer.com/article/10.1007/BF01963580

18. Belt H van den. Playing God in Frankenstein's Footsteps: Synthetic Biology and the Meaning of Life. NanoEthics. 2009 Nov 29;3(3):257-68.

19. Shaw A. "It just goes against the grain." Public understandings of genetically modified (GM) food in the UK. Public Underst Sci. 2002 Jul 1;11(3):273-91.

20. Pugh J. Playing God with mosquitoes? We humans have loftier aims [Internet]. The Conversation. [cited 2016 Apr 20]. Available from: http://theconversation.com/playing-god-with-mosquitoes-we-humanshave-loftier-aims-51362

21. Specter M. The Mosquito Solution. The New Yorker [Internet]. 2012 Jul 9 [cited 2016 Mar 22]; Available from: http://www.newyorker.com/magazine/2012/07/09/the-mosquitosolution

22. Sandel MJ. The Case Against Perfection. In: Savulescu J, Bostrom, N., editors. Human Enhancement. Oxford University Press; 2012.

23. Kamm F. Is There a Problem With Enhancement? Am J Bioeth. 2005;5(3):514.

24. Fang J. Ecology: A world without mosquitoes. Nat News [Internet]. 2010 Jul 21 [cited 2016 Feb 15];466(7305):432-4. Available from: http://www.nature.com/news/2010/100721/full/466432a.html

25. Savulescu J, Pugh J, Douglas T, Gyngell C. The moral imperative to continue gene editing research on human embryos. 2015;

26. Sunstein CR. Probability Neglect: Emotions, Worst Cases, and Law. Yale Law J. 2002;112(1):61-107. 